\title{
Synthesis and In vitro Cytotoxicity of a Novel Efficient Cisplatin-loaded Poly N-butyl Cyanoacrylate
}

\author{
Nahid Haghnazari ${ }^{1 *}$, Hadi Mohammadi ${ }^{2}$, Mohammad Javad Mokhtari ${ }^{3}$, Changiz Karami ${ }^{4}$ and Soheil \\ Ghasemi $^{5}$
}

${ }^{1}$ Department of biology, Faculty of Science, Sanandaj Branch, Islamic Azad University, Sanandaj-Iran.

${ }^{2}$ Young Researchers and Elite Club, Kermanshah Branch, Islamic Azad University, Kermanshah-Iran.

${ }^{3}$ Young Researchers and Elite Club, Zarghan Branch, Islamic Azad University, Zarghan-Iran.

${ }^{4}$ Department of Chemistry, Kermanshah Branch, Islamic Azad University, Kermanshah-Iran.

${ }^{5}$ Department of Pilot Nano biotechnology, Pasteur Institute of Iran, Tehran-Iran.

\begin{abstract}
Purpose: Typically, drug-loaded polymer colloidal carriers are synthesized by the drug entrapment during anionic emulsion polymerization. The purpose of this study was to trial the ability of Cisplatin-loaded Poly Butyl Cyanoacrylate (PBCA) nanoparticles. Methods: The cytotoxicity of Cisplatin-loaded PBCA nanoparticles was evaluated by MT assay. The Polymeric nanoparticles have been characterized using TEM, SEM, FTIR and DLS. Results: Polymeric nanoparticles with loaded and unloaded drug prepared by this method, have spherical structure with 350 and 230 $\mathrm{nm}$ in diameter and their zeta potentials were -3.2 and $-10.7 \mathrm{mv}$ respectively. The average amount of drug loaded on the nanoparticles was $70.88 \pm 5.51 \%$. MTT assay was carried out to evaluate the cytotoxicity property of the nanoparticles. Inhibition concentration values $\left(\mathrm{IC}_{50}\right)$ for Cisplatin-loaded Nanoparticles were 20.8 and 18.2 $\mu \mathrm{M}$ for 24 and $48 \mathrm{~h}$ respectively. Conclusion: It was shown that cisplatin-loaded nanoparticles strongly increased cytotoxicity in comparison to classic drug in the MCF-7 cell line.
\end{abstract}

Key words: Cisplatin, Drug delivery, Emulsion polymerization, Encapsulation, Polymeric Nanoparticles.

\section{INTRODUCTION}

The Poly Alkyl Cyanoacrylate (PACA) polymers are biocompatible, biodegradable and low-toxic materials, accepted for human usage (the respective monomers are used as surgical glues).,2 The PACA nanoparticles are among the most perspective nano sized drug carriers attracting a great interest for application in targeted delivery of different biologically active substances such as anticancer agents $s^{3,4}$ antibiotics $^{5-7}$ peptides $^{8,9}$ nucleic acids ${ }^{10}$ and antiviral drugs. ${ }^{11}$ in 1979 the PACA nanoparticles have been prepared for the first time by emulsion polymerization of alkyl cyanoacrylate monomer in acidic aqueous solution. ${ }^{12}$ Since then, the emulsion polymerization has been intensively applied for the entrapment of various drugs in PACA nanoparticles under different conditions. The utilization of this method resulted in a significant advance- ment of the development of novel nanoformulations of classical drugs however, a number of serious limitations still exist. For example, the molecular weight of the formed polymer and the nanoparticle size depend strongly on the polymerization conditions, being sometimes difficult to control $^{13-15}$ Also, certain chemically sensitive drugs could be unstable in the conditions of the polymerization reaction or might initiate the polymerization, being conclusively deactivated by the highly reactive monomer. ${ }^{16}$ The emulsion polymerization is still more popular and widely used method for the preparation of PACA nanoparticles. N-butyl cyanoacrylate monomer has been used in the synthesis of nanoparticles by dispersion of monomers in aqueous media. Drug-loaded PBCA carriers are prepared by the drug entrapment during emulsion
Submission Date : 11-03-2015 Revision Date : :25-05-2015 AcceptedDate : :26-06-2015

DOI: 10.5530/ijper.50.1.23 Correspondence Address Dr. Nahid Haghnazari Department of biology, Faculty of Science,

Sanandaj Branch, Islamic Azad University, Sanandaj-Iran. POBox:67185-113, Kermanshah, Iran. E-mail:n.haghnazari@gmail. com

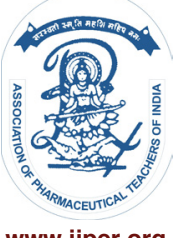

www.ijper.org 


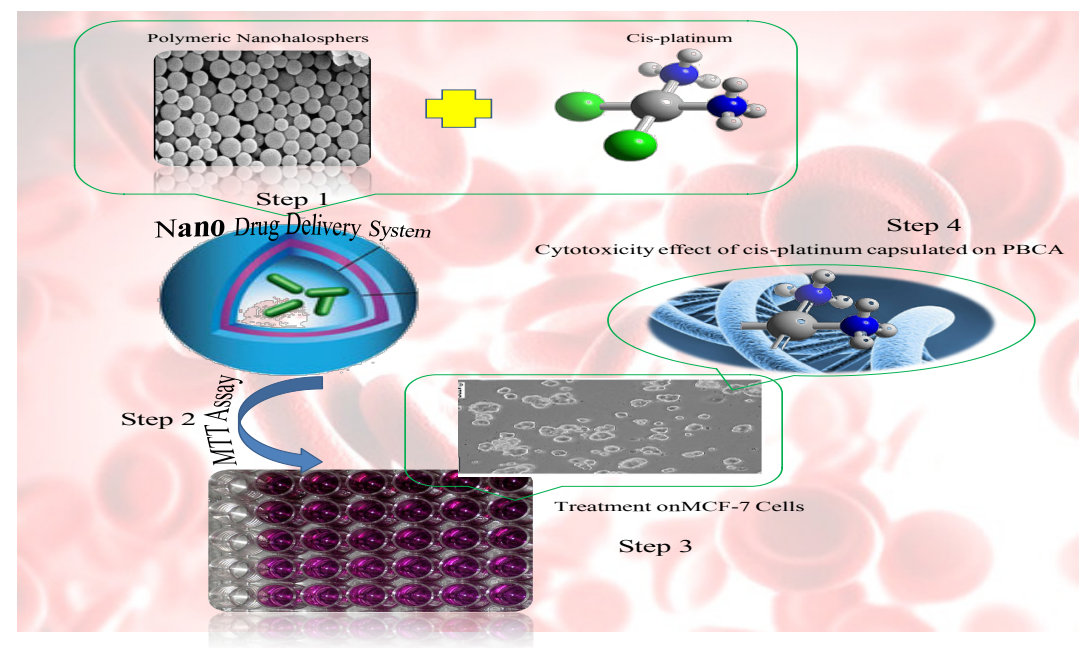

\section{Graphical Abstract}

polymerization. In this research the anionic emulsion polymerization method was employed for the preparation of pure and drug loaded PBCA nanoparticles was investigated. This method permits the effective entrapment of lipophilic and chemically labile drugs through avoiding the contact with highly reactive monomers.

Platinum complexes currently make up one of the three most widely used groups of anticancer drugs in the world. ${ }^{17}$ in 1960s The anticancer action of cisplatin was exposed serendipitously. ${ }^{18}$ Meanwhile in 1978 it has been used in clinics in contradiction of a diversity of cancers including ovarian, testicular, bladder, head and neck, lymphoma, cervical and melanoma. Treatment with cisplatin regularly reasons severe side effects for example vomiting, nausea, neurotoxicity, nephrotoxicity, emetogenesis and myelotoxicity. ${ }^{17}$ These side effects rise mostly as a result of the limited selectivity of cisplatin for tumor cells as compared to healthy cells ${ }^{19}$ and may similarly be due to reactions with Thiol containing types in blood plasma, such as cysteine and human serum albumin. ${ }^{18}$ The cellular mechanisms of cisplatin resistance have been identified. ${ }^{20}$

The highest factors that modulate resistance include, declined drug accumulation and increased levels of intracellular Thiols that can deactivate cisplatin and capability of cells to repair or tolerate DNA damage caused by cisplatin. Other processes have also been implicated. In the present study, cisplatin anticancer drug was chosen as the model drug for the incorporation pure and drug-loaded nanoparticles, which are easily prepared by the anionic emulsion polymerization method. Finally, effects of cisplatin and cisplatin-loaded nanoparticles on the viability of MCF-7 cell line were evaluated at different concentrations at 24 and $48 \mathrm{~h}$.

\section{EXPERIMENTAL SECTION}

\section{Materials}

Reagents and solvents were commercially accessible and used as supplied deprived of further purification. N-butyl cyanoacrylate monomer was prepared from Tong Shen ${ }^{\circledR}$ (China). Phosphate-buffered saline (PBS, tablets; $p \mathrm{H}=7.4)$, sodium hydroxide $(>99 \%)$, Dextran $70 \mathrm{kDa}(\mathrm{Mr}=70,000)$, Cisplatin, Hydrochloric Acid was from Merck $^{\circledR}$ (Germany). Mannitol was from Sigma ${ }^{\circledR}$ (Germany). Distilled water was used for all preparations. MCF-7 (Human breast adenocarcinoma cell line) cell line was obtained from National Cell Bank of Iran (NCBI), Pasteur Institute of Iran.

\section{Preparation of PBCA nanoparticles}

The pure PBCA nanoparticles were prepared by anionic emulsion polymerization by following method.The polymerization medium was prepared by dissolving Dextran $70 \mathrm{kDa}(500 \mathrm{mg})$ in distilled water $(200 \mathrm{ml})$. Then, the n-butyl cyanoacrylate monomer $(2.0 \mathrm{ml})$ was added drop wise to the polymerization medium upon vigorous mechanical stirring $(600 \mathrm{rpm})$. The emulsion became milky white within the first $20 \mathrm{~min}$ and was left to polymerize for $4 \mathrm{~h}$. The $\mathrm{pH}$ of the obtained dispersion was adjusted at 5-6 via adding of $1 \mathrm{~N} \mathrm{NaOH}(4.0$ $\mathrm{ml})$. The polymer dispersion was centrifuged (15000 $\mathrm{rpm}, 25 \mathrm{~min}$ ) and washed twice with distilled water by centrifugation. The white sediment was then dried under vacuum to obtain fine white powder. ${ }^{21}$

For synthesis of drug-loaded PBCA nanoparticles, alike process was used where cisplatin anticancer drug solution (50 mg/100 ml) was added throughout PBCA synthesized, in order to cisplatin entrapped in the PBCA nanoparticles. Furthermore the reaction time was decreased to $2.5 \mathrm{~h}$. 


\section{Methods of characteristic pure PBCA and drug loaded PBCA}

\section{Particle Size and Morphology}

The pure and cisplatin loaded PBCA nanoparticles were imaged by a SEM, XL 30, Philips ${ }^{\circledR}$ and particle morphology were observed by TEM using EM208, Philips ${ }^{\circledR}$ at $100 \mathrm{kV} .1 \mathrm{~mL}$ dispersion was diluted with $1 \mathrm{~mL}$ deionized water and a drop of it was placed onto a collodion support on copper grids (400 meshes). About 2 min of deposition, the grid was tapped with a filter paper to remove surface water and negatively stained by using a sodium phosphotungstate for 5 seconds. The grid was allowed to dry further for 10 minutes and was then examined with the electron microscope. The particle size distribution was measured by DLSS $1000 \mathrm{HSA}$, Malvern Instruments Ltd., and Worcestershire, UK (Each value was obtained as average of their measurements). The colloidal suspension of the nanoparticles were diluted with deionized distilled water, and the particle size analysis was carried out at a scattering angle of $90^{\circ}$ and a temperature of $25^{\circ} \mathrm{C}$.

\section{Zeta-Potential}

The measurement of zeta potential was done in $10 \mathrm{mM}$ $\mathrm{NaCl}$ using disposable zeta cells and the general purpose protocol at $25^{\circ} \mathrm{C}$. The instrument was calibrated routinely with a $-50 \mathrm{mV}$ latex standard. The mean zeta potential was determined by phase analysis light scattering technique.

\section{Functional Groups}

FTIR spectra of the powdered samples were taken as $1 \%$ dispersion in $\mathrm{KBr}$ pellets on a spectrometer Thermo Nicolet $^{\circledR}$ (Nexus 870, USA). The samples were scanned from $500-4000 \mathrm{~cm}^{-1}$.

\section{Drug-Loading Efficiency}

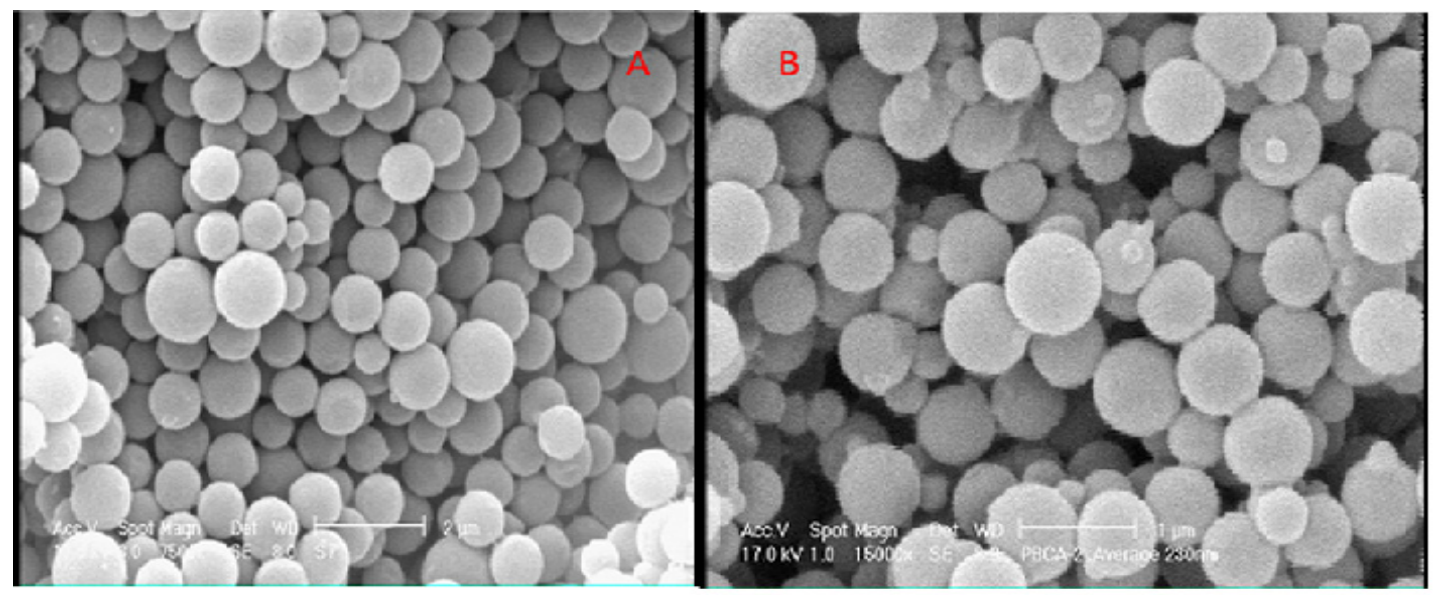

Figure 1: Morphology of the (a) pure PBCA nanoparticles and (b) PBCA loaded cisplatin determined by SEM
The cisplatin content was assessed by AAS (Contra 700, Analytik Jena, Germany) using $\mathrm{H}_{2} \mathrm{PtCl}_{6}\left(\mathrm{Sigma}^{\circledR}\right)$ as a standard. Absorbance was read at $265 \mathrm{~nm}$. All experiments were repeated three times and the percentage of cisplatin loading was calculated by the following equation which was derived empirically at our laboratory.

\% Loading Encapsulation = 1-quantity of Pt in the supernatant fluid $\mathrm{x} 100$

\section{Cell Line and Cell Culture}

MCF-7 cell line (human breast adenocarcinoma cell) was obtained from National Cell Bank of Iran (NCBI, Pasteur Institute). Cells were maintained in RPMI 1640 medium supplemented with 10\% fetal bovine serum and $2 \mathrm{mM}$ glutamine. Cells were allowed to grow in plastic tissue culture flasks and were kept in $\mathrm{CO}_{2}$ incubator at $37^{\circ} \mathrm{C}$ in a humidified atmosphere of $5 \% \mathrm{CO}_{2}$ and $95 \%$ air. $^{22}$

\section{Cell Treatment and MTT assay}

MCF-7 Cell were cultured in 96-well plates at a density of $10^{4}$ cells/well and treated with different concentrations of cisplatin and cisplatin loaded nanoparticles at a final cisplatin concentration of $0,15,30,60$ and $120 \mu \mathrm{M}$ at 24 and $48 \mathrm{~h}$ incubation. Each concentration was tested on six wells of the 96-well plates. The response of cell to compounds were evaluated by determining cell survival using 3-(4, 5-dimethylthiazol-2-yl) 2, 5-diphenyl tetrazolium bromide (MTT', Carl Roth, Karlsruhe, Germany). 10 $\mu$ of MTT solution ( $5 \mathrm{mg} / \mathrm{ml}$ in PBS) was added to cell monolayer in each 96-well plates. Cells were incubated in a humidified incubator at $37^{\circ} \mathrm{C}$ for $3 \mathrm{~h}$ and the absorbance was measured at $540 \mathrm{~nm}$ by an ELISA reader. The positive control contained six MCF-7 seeding cell, incubated with $100 \mu \mathrm{l}$ deionized distilled water for $10 \mathrm{~min}$. $\mathrm{IC}_{50}$ of cisplatin and cisplatin-loaded PBCA nanoparticles on MCF-7 cells at $24 \mathrm{~h}$ which were calculated by probity analysis using the Pharm PCS (Pharmacologic Calculation System) statistical package (Springer Verlag, USA). ${ }^{23}$ 


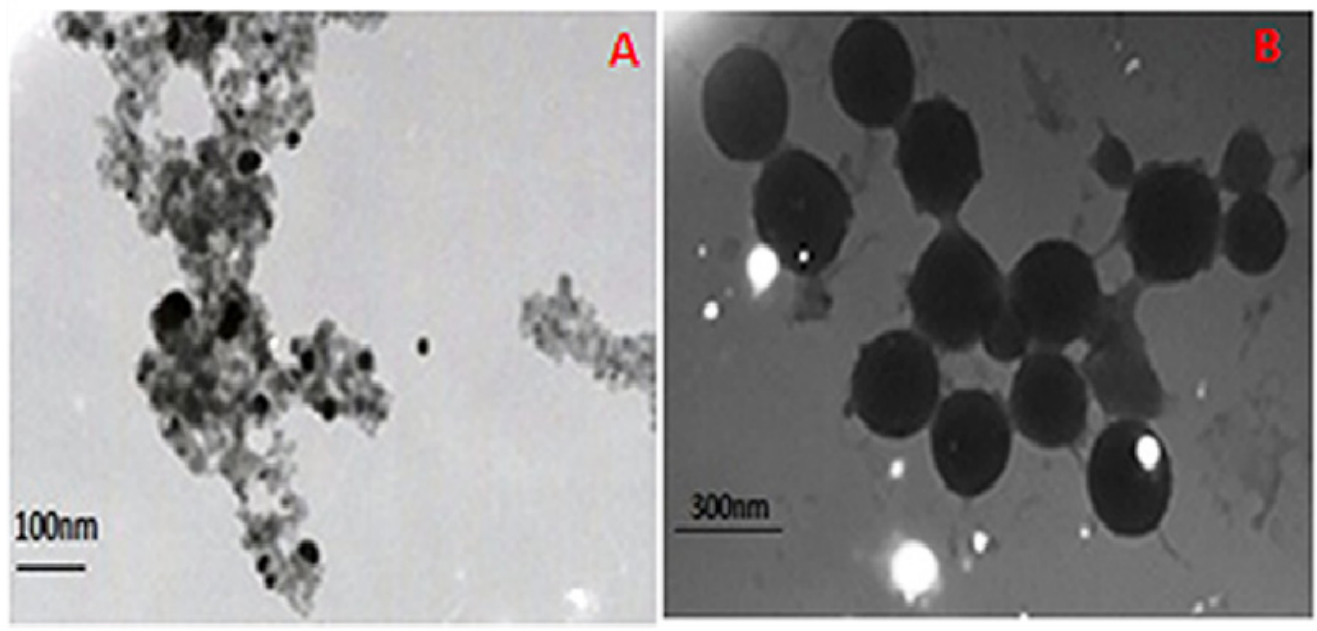

Figure 2: Morphology of the (a) pure PBCA nanoparticles and (b) PBCA loaded cisplatin determined by TEM

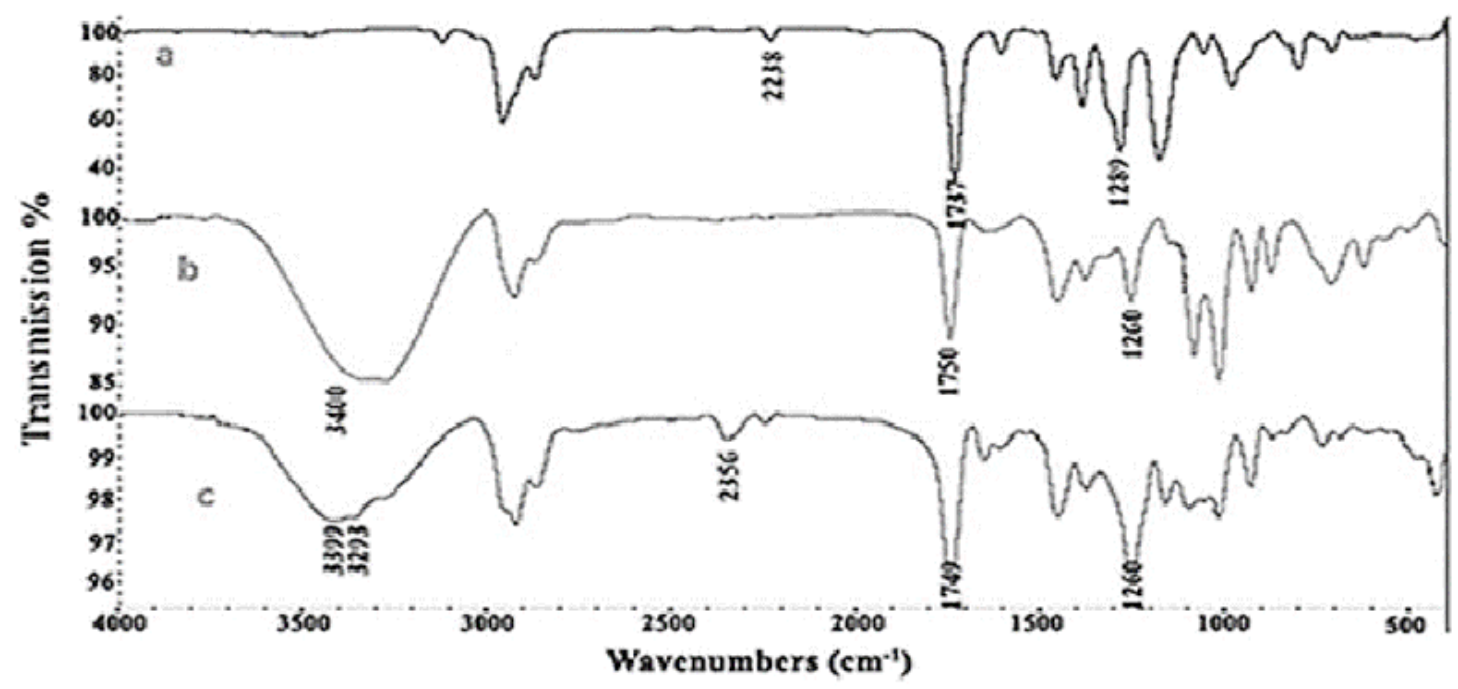

Figure 3: FTIR spectra of (a) n-butyl cyanoacrylate (b) PBCA nanoparticles and (c) cisplatin loaded PBCA. Nanoparticles

\section{Statistical Analysis}

Results were expressed as mean \pm SD. Throughout this study statistical significance of difference was calculated by one-way variance analysis using Student's t-test.

\section{RESULTS AND DISCUSSION}

\section{Preparation and Characterization}

\section{Particle Size and Morphology}

The nanoparticle suspensions were investigated by SEM, without further purification. The particles size of pure PBCA and cisplatin loaded PBCA were measured by SEM where the average size of the particles were about 230 and $350 \mathrm{~nm}$, respectively (Figure 1). Typical TEM micrograph of pure PBCA and cisplatin loaded PBCA was shown in (Figure 2). The observed results with the SEM and TEM, show that the particles of pure
PBCA and cisplatin loaded PBCA are spheroid, with smooth surface. After loading, the size of particles was increased, indicating incorporation of cisplatin drug in the PBCA nanoparticles. This means cisplatin loaded PBCA nanoparticles have typical nano-material characteristics and can be efficiently taken up by cells.

\section{FTIR Spectra of n-Butyl Cyanoacrylate, PBCA Nanoparticles and Cisplatin Loaded PBCA Nanoparticles}

The PBCA nanoparticles were synthesized by dropping monomer into an acidic solution of dextran 70 $\mathrm{kDa}$. The polymerization is stopped by $\mathrm{NaOH}$ solution after $4 \mathrm{~h}$. The uniform PBCA particles were obtained at room temperature. The FTIR spectra of monomer and polymer of BCA were recorded from $500-4000 \mathrm{~cm}^{-1}$ (Figure 3). The $\mathrm{C}-\mathrm{O}, \mathrm{C}=\mathrm{O}$ (from ester function) and $\mathrm{C} \equiv \mathrm{N}$ stretching bonds appear at 1289, 1737 and 2238 $\mathrm{cm}^{-1}$ for monomer and 1260, 1750 and $2357 \mathrm{~cm}^{-1}$ for 


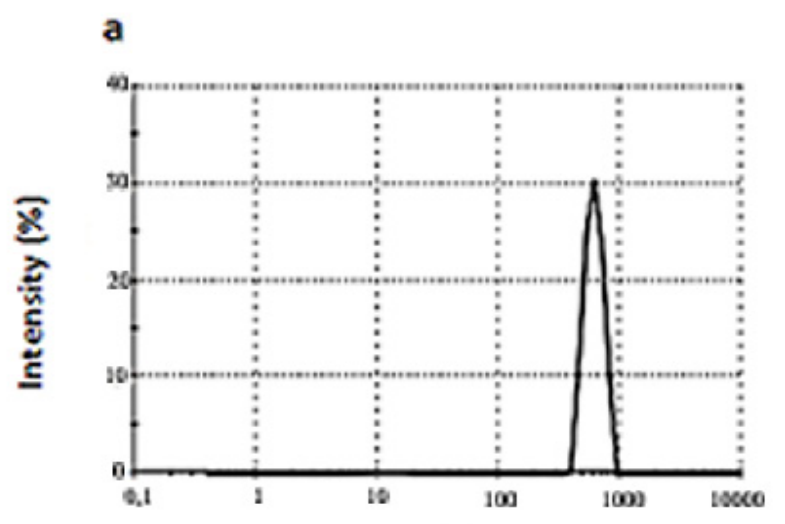

Size $(\mathrm{nm})$

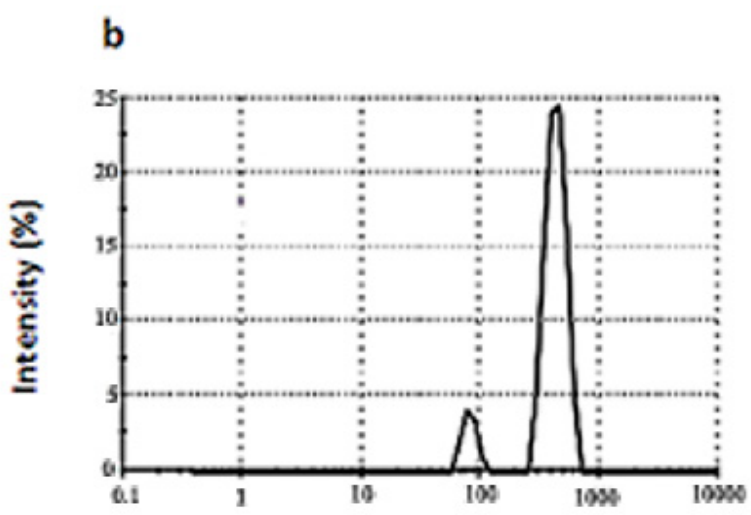

Size $(\mathrm{nm})$

Figure 4: Distribution of the diameter of the (a) pure PBCA and (b) cisplatin loaded PBCA nanoparticles

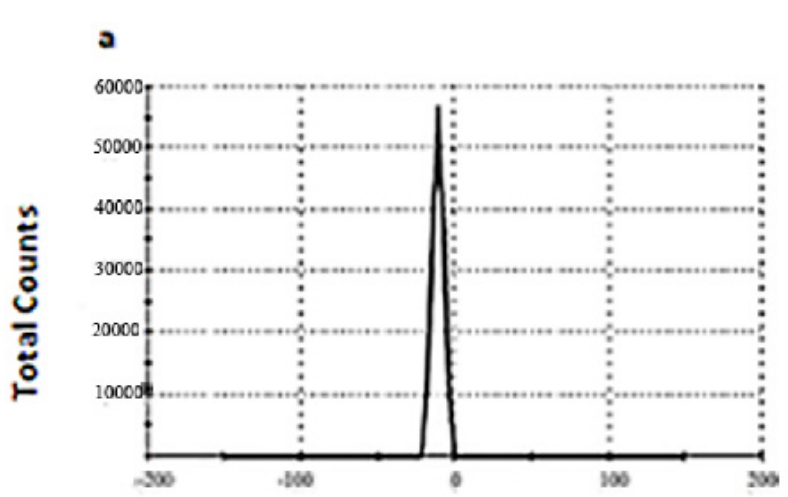

Zeta Potential (mV)

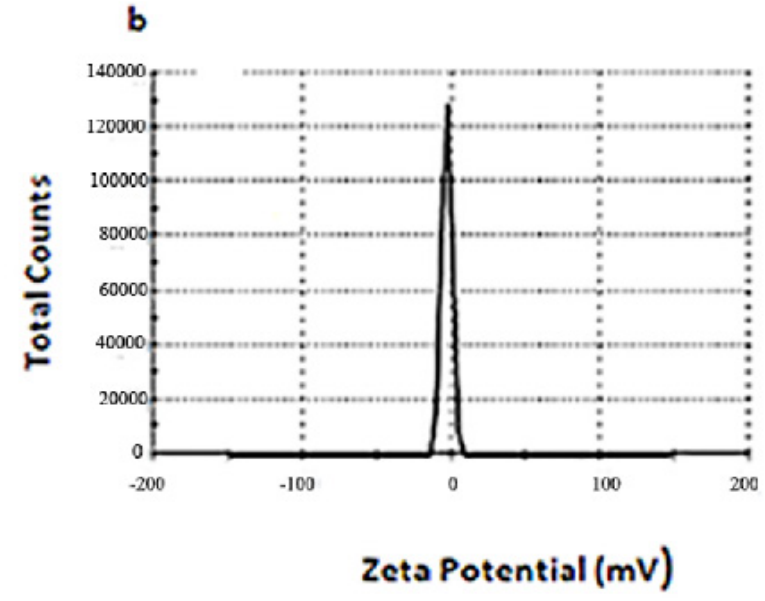

Figure 5: Charge distribution of the (a) pure PBCA and (b) cisplatin loaded PBCA nanoparticles
PBCA, respectively. ${ }^{24}$ Drug loaded nanoparticles were synthesized according to the described method with adding Cisplatin during polymerization of n-butyl cyanoacrylate. The FTIR pattern of cisplatin loaded PBCA nanoparticles are very close to that of pure PBCA nanoparticles because stretch mode of $\mathrm{Pt}-\mathrm{Cl}$ and $\mathrm{Pt}-\mathrm{N}$ bonds appear far IR, below $400 \mathrm{~cm}^{-1}$.

\section{Loading Efficiency of PBCA nanoparticles with Cisplatin Drug}

Loading encapsulation of PBCA nanoparticles with Cisplatin drug was determined by AAS. Relative drug loading ( $\%$ of total amount) was calculated by subtraction of free drug in the supernatant from the total amount in the vials and the percentage of cisplatin loading were calculated by the above equation, where the average loading efficiency was $70.88 \pm 5.51 \%$.

\section{Size Distributions and Zeta Potential of Nanoparticles}

DLSS measurements require a larger number of particles (several orders of magnitude greater) compared to SEM, and thus provide much better statistics. They primarily yield diffusion coefficient distributions which, however, can be transformed into distributions of hydrodynamic diameters. Using the same particle of PBCA as in SEM, DLSS measurements were performed on both pure and cisplatin-loaded PBCA nanoparticles that yielded the size distributions shown in (Figure 4). Uniform intensity weighted diameter of 200-400 nm was found for pure PBCA where cisplatin-loaded PBCA nanoparticles exhibited two size distributions one at 50-60 nm with low intensity, another at 300-500 $\mathrm{nm}$ with high intensity. The difference between the two values may be due to the presence of cisplatin in the last distribution. The morphology and size distribution of the nanoparticles 


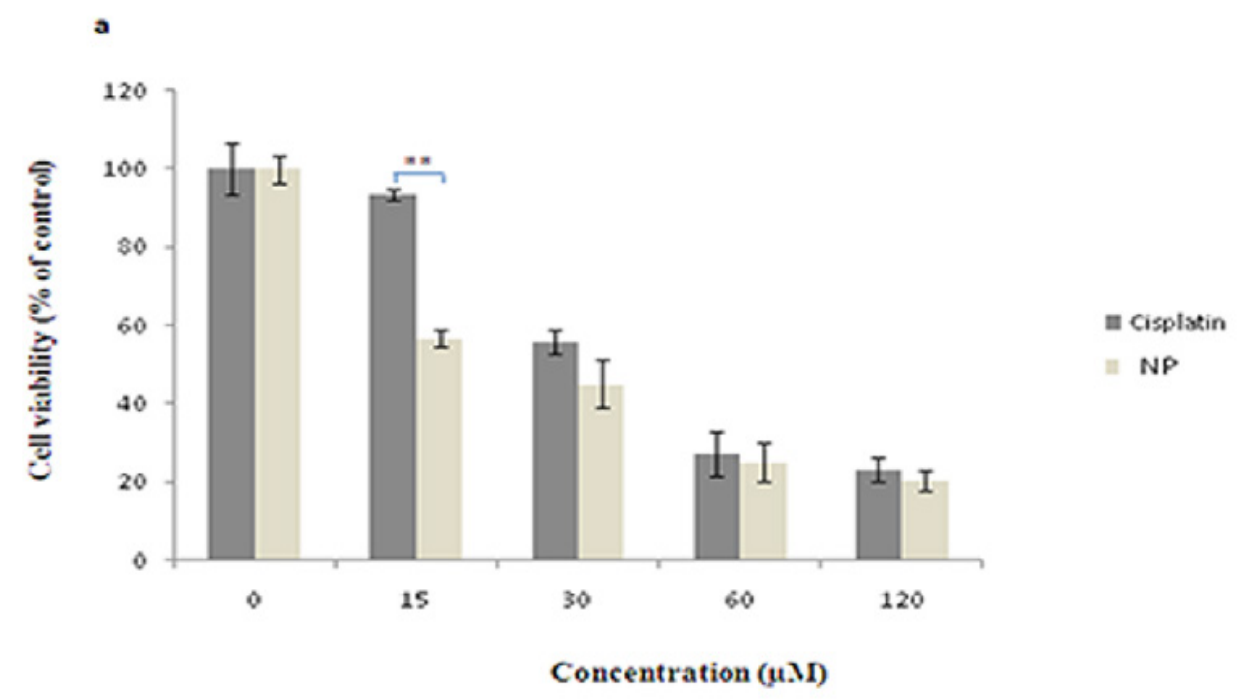

Figure 6(a): Cytotoxicity of free cisplatin and cisplatin loaded nanoparticles (NP) on MCF-7 cells at 24h

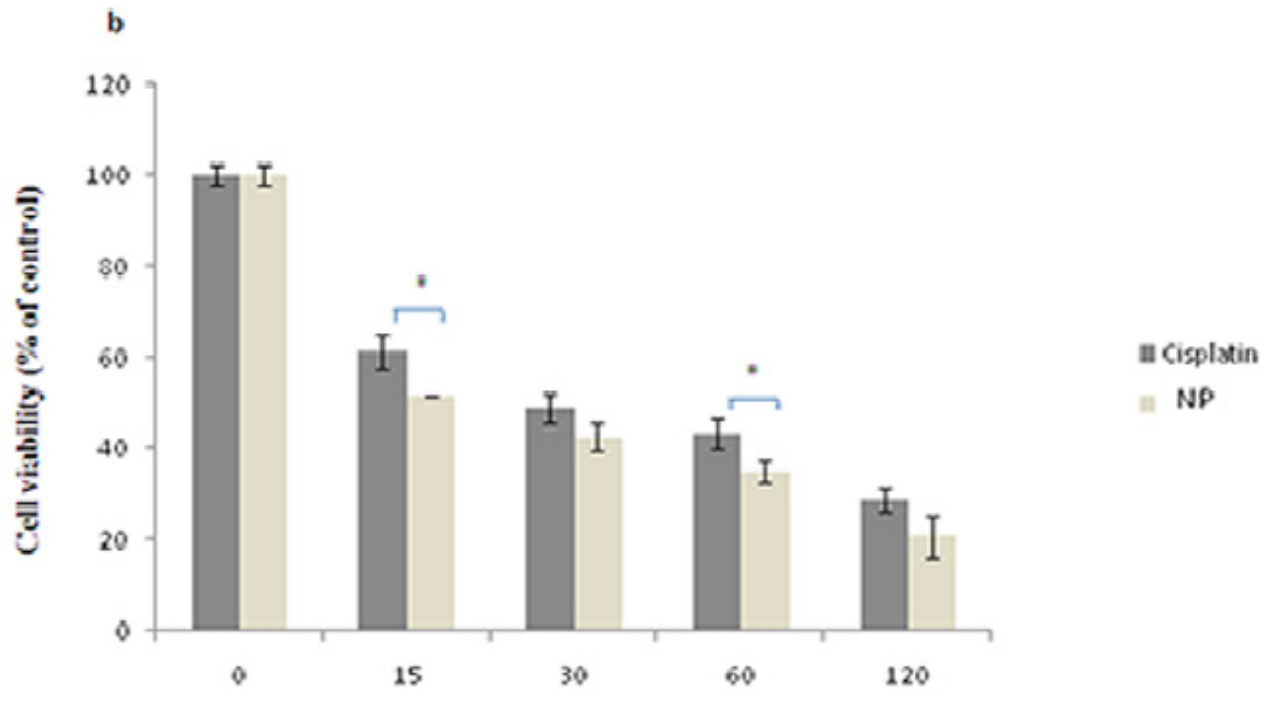

Concentration $(\mu . \mathrm{N})$

Figure 6(b): Cytotoxicity of free cisplatin and cisplatin loaded nanoparticles (NP) on MCF-7 cells at $48 \mathrm{~h}$. Results are expressed as a percentage of viability compared to control and are presented as mean $\pm S D$ from at least three independent experiments $\left({ }^{*} \mathrm{P}<0.05\right.$; $\left.{ }^{* *} \mathrm{P}<0.001\right)$

demands the anionic emulsion polymerization method and leads to uniform spherical nanoparticles.

Zeta potential study was also performed to determine surface charge of nanoparticles, as shown in (Figure 5). Pure PBCA nanoparticles showed negative zeta-potential in distilled water, with a value of-10.7 $\mathrm{mV}$ a general phenomenon of theoretically uncharged polymeric particle. Loading of cisplatin on the nanoparticles exchange the charge towards a positive value, resulted to- $3.2 \mathrm{mV}$ surface charge for cisplatin-loaded PBCA nanoparticles.

\section{In vitro cytotoxicity and $\mathrm{IC}_{50}$ determination}

Experimental cytotoxic concentrations of cisplatin and cisplatin-loaded nanoparticles ranged from 0 to $120 \mu \mathrm{M}$. MCF-7 cells viability curve after 24 and $48 \mathrm{~h}$ incubation with Cisplatin and cisplatin-loaded nanoparticles were presented on Figure 6. After $24 \mathrm{~h}$, compared to the controls, the lower dose of cisplatin and cisplatinloaded nanoparticles $(15 \mu \mathrm{M})$ 6.674\% (difference not significant, $\mathrm{p}>0.05)$ and $43.334 \%(\mathrm{p}<0.001)$, and the higher dose of cisplatin and cisplatin-loaded nanoparti- 
cles $(120 \mu \mathrm{M}) 76.853 \%(\mathrm{p}<0.001)$ and $79.8 \%(\mathrm{p}<0.001)$ decreased in total cell number, respectively. The $\mathrm{IC}_{50}$ of cisplatin and cisplatin-loaded nanoparticles were calculated to be $45.594 \mu \mathrm{M}$ and $20.824 \mu \mathrm{M}$, respectively. After $48 \mathrm{~h}$, compared to the controls, the lower dose of cisplatin and cisplatin-loaded nanoparticles $(15 \mu \mathrm{M}) 38.66 \%$ $(\mathrm{p}<0.001)$ and $48.534 \%(\mathrm{p}<0.001)$, and the higher dose of cisplatin and cisplatin-loaded nanoparticles $(120 \mu \mathrm{M})$ $71.334 \%(p<0.001)$ and $79.317 \%(p<0.001)$ decreased in total cell number, respectively. The $\mathrm{IC}_{50}$ of cisplatin and cisplatin loaded nanoparticles were calculated to be $31.300 \mu \mathrm{M}$ and $18.220 \mu \mathrm{M}$, respectively. The cisplatin loaded nanoparticles exhibited in vitro anticancer activity comparable to that of free cisplatin. The cytotoxic activity of both cisplatin and cisplatin-loaded nanoparticles increased with increasing cisplatin concentration.

\section{CONCLUSION}

The objective in developing drug delivery systems is to achieve high drug concentration in diseased tissue and low concentration in healthy tissue and the rest of the body. Polymeric nanoparticles offer a possibility to achieve this goal. Over the past few years many studies have focused on the use of PBCA nanoparticles as carriers for a number of different drugs (e.g. doxorubicin, cyclosporine A, MRZ 2/596, a novel NMDA-receptor antagonist) the present work is a simple emulsion polymerization approach to synthetized polymeric nanoparticles, in which n-butyl cyanoacrylate monomer added to Dextran $70 \mathrm{kDa}$ in the presence of cisplatin anticancer drug. Pure and drug-loaded nanoparticles are successfully prepared using Dextran $70 \mathrm{kDa}$ as stabilizers. The size of these cisplatin-loaded PBCA nanoparticles were formulated to $\sim 350 \mathrm{~nm}$ which is an important parameter for enhancing the circulation life time and ensuring diffusion of particles into tumor sites. The zeta potential of cisplatin loaded PBCA nanoparticles were- $3.2 \mathrm{mV}$. The formulated cisplatin-loaded PBCA nanoparticles effectively inhibits proliferation in breast cancer cell lines.

\section{SUMMARY}

- Polymeric nanoparticles with loaded and unloaded drug prepared by anionic emulsion polymerization method, have spherical structure.

- The average amount of drug loaded on the nanoparticles was $70.88 \pm 5.51 \%$.

- The cytotoxicity of Cisplatin-loaded PBCA nanoparticles was measured by MTT assay.

- Inhibition concentration values $\left(\mathrm{IC}_{50}\right)$ for Cisplatin-loaded Nanoparticles were 20.8 and $18.2 \mu \mathrm{M}$ for 24 and 48 $\mathrm{h}$ respectively

\section{About Authors}

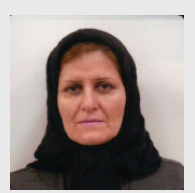

Dr. Nahid Haghnazari: Nahid Haghnazari is an assistant professor at the department of Bio-chemistry, Islamic Azad University Sanandaj, Iran . Her research interest is in the area of Nano-Biosensors and Nanodrug delivery. She has 10 Nos of journal paper, 2 Nos of book and 4 invited talk.

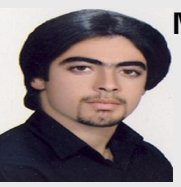

Mr. Hadi Mohammadi: presently working as Research and Teaching assistant in Islamic azad university of Kermanshah, he has been membership through the Young Researchers and Elite Club, Kermanshah $\mathrm{B} \mathrm{r}$ a n c h, Islamic Azad University, Kermanshah for 8 years also. He has 9 nos. of journal paper; more than 15 nos. of conferences paper; 2 invited talk; Acting as Co-PI in two (2) ongoing projects. Hadi is also one of the lecturers through the Iran Nanotechnology Organisation. His main research interests are nanochemistry, drug delivery applications of nano materials along with evaluation of new inorganic nano catalyst and photo catalyst compounds for various reactions.

Dr. Mohammad Javad Mokhtari: Dr. M. J. Mokhtari working as teacher and researcher in the Department of Genetic, Zarghan Branch, Islamic Azad University,
Zarghan, Iran. I have 10 nos. of journal paper; 20 nos. of abstract; 1 nos. of book. My interests are nano drug delivery, cell culture methods and oncology.

Changiz Karami: received in 2004 his BSc in chemistry from the Department of Chemistry at Razi University of Kermanshah, Iran. Then, he joint to Azad university of Kermanshah (2004) for working in the organic lab and obtained his MSc in organic chemistry from Department of Chemistry at Razi University of Kermanshah, Iran in 2008. Since 2013 he is a PhD candidate of nano chemistry in Department of Chemistry of Shahid Bahonar University of Kerman, Iran and his main research interests are nano-chemistry, nano materials, catalyst and drug delivery applications.

Soheil Ghasemi: Biotechnology $\mathrm{PhD}$ candidate in Pasteur Institute of Iran and received his MSc in Cellular \& Molecular Biology from the Azad University of Science \& Research Branch, Tehran, Iran (2009). He then worked at the Pasteur Institute of Iran for 5 years and, subsequently, at pharmaceutical companies as researcher to develop the new methods. His main research interests are molecular biology, drug delivery and drug development. 


\section{ACKNOWLEDGEMENTS}

The authors are grateful to the Department of biology, Faculty of Science, Sanandaj Branch, Islamic Azad University, Sanandaj, Iran for the financial support for this research.

\section{REFERENCES}

1. Vauthier C, Christine, et al. Poly (alkylcyanoacrylates) as biodegradable materials for biomedical applications. Advanced drug delivery reviews 2003; 55(4): 519-48.

2. Oowaki $\mathrm{H}$, et al. Non-adhesive cyanoacrylate as an embolic material for endovascular neurosurgery. Biomaterials 2000; 21(10): 1039-46.

3. Petri B, et al, Chemotherapy of brain tumour using doxorubicin bound to surfactant-coated poly (butyl cyanoacrylate) nanoparticles: revisiting the role of surfactants. Journal of Controlled Release 2007; 117(1): 51-8.

4. Arias JL, et al. Poly (alkylcyanoacrylate) colloidal particles as vehicles for antitumour drug delivery: a comparative study. Colloids and Surfaces B: Biointerfaces 2008; 62(1): 64-70.

5. Pinto-Alphandary HA, Andremont P, Couvreur. Targeted delivery of antibiotics using liposomes and nanoparticles: research and applications. International Journal of antimicrobial agents 2000; 13(3): 155-68.

6. Merchan M, et al. Antibacterial polyvinyl chloride/antibiotic films: The effect of solvent on morphology, antibacterial activity, and release kinetics. Journal of applied polymer science 2010; 118(4): 2369-78.

7. Fontana $\mathrm{G}$, et al. Amoxicillin-loaded polyethylcyanoacrylate nanoparticles: influence of PEG coating on the particle size, drug release rate and phagocytic uptake. Biomaterials 2001; 22(21): 2857-65.

8. Zhang QZ, Shen T, Nagai. Prolonged hypoglycemic effect of insulin-loaded polybutylcyanoacrylate nanoparticles after pulmonary administration to normal rats. International Journal of pharmaceutics 2001; 218(1): 75-80.

9. Graf A, et al. Protein delivery using nanoparticles based on microemulsions with different structure-types. european Journal of pharmaceutical sciences 2008; 33(4): 434-44.

10. Lambert G, et al. Polyisobutylcyanoacrylate nanocapsules containing an aqueous core as a novel colloidal carrier for the delivery of oligonucleotides. Pharmaceutical research 2000; 17(6): 707-14.

11. Kuo Y-C. Loading efficiency of stavudine on polybutylcyanoacrylate and methylmethacrylate-sulfopropylmethacrylate copolymer nanoparticles. International Journal of pharmaceutics 2005; 290(1): 161-72.
12. Couvreur $P$, et al. Polycyanoacrylate nanocapsules as potential lysosomotropic carriers: preparation, morphological and sorptive properties. Journal of pharmacy and pharmacology 1979; 31(1): 331-2.

13. Leonard $\mathrm{F}$, et al. Synthesis and degradation of poly (alkyl a-cyanoacrylates). Journal of applied polymer science 1966; 10(2): 259-72.

14. Douglas SL, Illum, Davis S. Particle size and size distribution of poly (butyl 2-cyanoacrylate) nanoparticles. II. Influence of stabilizers. Journal of colloid and interface science 1985; 103(1): 154-63.

15. Alonso $\mathrm{M}$, et al. Joint effects of monomer and stabilizer concentrations on physico-chemical characteristics of poly (butyl 2-cyanoacrylate) nanoparticles. Journal of microencapsulation 1990; 7(4): 517-26.

16. Braunecker WA, Matyjaszewski K. Controlled/living radical polymerization: features, developments, and perspectives. Progress in Polymer Science 2007; 32(1): 93-146.

17. Abu-Surrah AS, Kettunen M. Platinum group antitumor chemistry: design and development of new anticancer drugs complementary to cisplatin. Current medicinal chemistry 2006; 13(11): 1337-57.

18. Alderden RA, Hall MD, Hambley TW. The Discovery and Development of Cisplatin. Journal of Chemical Education 2006; 83(5): 728.

19. Langer $M$, et al. Novel Peptide Conjugates for Tumor-Specific Chemotherapy. Journal of Medicinal Chemistry 2001; 44(9): 1341-8.

20. Stordal B, Davey M. Understanding cisplatin resistance using cellular models. IUBMB life 2007; 59(11): 696-9.

21. Behan N, Birkinshaw C, Clarke N. Poly $n$-butyl cyanoacrylate nanoparticles: a mechanistic study of polymerisation and particle formation. Biomaterials 2001; 22(11): 1335-44.

22. Banerjee SS, Chen D-H. Magnetic nanoparticles grafted with cyclodextrin for hydrophobic drug delivery. Chemistry of Materials 2007; 19(25): 6345-9.

23. Mokhtari MJ, et al. Evaluation of Cisplatin and Cisplatin-loaded Magnetic Iron Oxide Nanoparticles on BCL2 and BAX genes in the Breast Cancer T47D Cell Line. Modares Journal of Medical Sciences: Pathobiology 2012; 15(4): 75-87.

24. Duan J, et al, Cationic polybutyl cyanoacrylate nanoparticles for DNA delivery. Bio Med Research International 2009; 2009(2009): Article ID 149254, 9. DOI: $101155 / 2009 / 149254$ 